\title{
The Transcription Factors Islet and Lim3 Combinatorially Regulate Ion Channel Gene Expression
}

\author{
Verena Wolfram, ${ }^{1}$ Tony D. Southall, ${ }^{2}$ Cengiz Günay, ${ }^{3}$ Astrid A. Prinz, ${ }^{3}$ Andrea H. Brand, ${ }^{2}$ and Richard A. Baines ${ }^{1}$ \\ ${ }^{1}$ Faculty of Life Sciences, University of Manchester, Manchester M13 9PT, United Kingdom, ${ }^{2}$ The Gurdon Institute and Department of Physiology, \\ Development and Neuroscience, University of Cambridge, Cambridge CB2 1QN, United Kingdom, and ${ }^{3}$ Department of Biology, Emory University, Atlanta, \\ Georgia 30322
}

Expression of appropriate ion channels is essential to allow developing neurons to form functional networks. Our previous studies have identified LIM-homeodomain (HD) transcription factors (TFs), expressed by developing neurons, that are specifically able to regulate ion channel gene expression. In this study, we use the technique of DNA adenine methyltransferase identification (DamID) to identify putative gene targets of four such TFs that are differentially expressed in Drosophila motoneurons. Analysis of targets for Islet (Isl), Lim3, $\mathrm{Hb}$, and Even-skipped (Eve) identifies both ion channel genes and genes predicted to regulate aspects of dendritic and axonal morphology. Significantly, some ion channel genes are bound by more than one TF, consistent with the possibility of combinatorial regulation. One such gene is Shaker $(S h)$, which encodes a voltage-dependent fast $\mathrm{K}^{+}$channel $\left(\mathrm{K}_{\mathrm{v} 1.1}\right)$. DamID reveals that $S h$ is bound by both Isl and Lim3. We used body wall muscle as a test tissue because in conditions of low $\mathrm{Ca}^{2+}$, the fast $\mathrm{K}^{+}$current is carried solely by Sh channels (unlike neurons in which a second fast $\mathrm{K}^{+}$current, Shal, also contributes). Ectopic expression of isl, but not Lim3, is sufficient to reduce both $S h$ transcript and Sh current level. By contrast, coexpression of both TFs is additive, resulting in a significantly greater reduction in both Sh transcript and current compared with isl expression alone. These observations provide evidence for combinatorial activity of Isl and Lim3 in regulating ion channel gene expression.

Key words: aCC; central nervous system; Drosophila; muscle; RP3; Shaker

\section{Introduction}

The development of embryonic neurons is regulated by factors that are intrinsic or extrinsic to individual cells. It is, however, in the early stages of development, before axonal growth and circuit formation, that intrinsic factors predominate (Spana et al., 1995; Grosskortenhaus et al., 2005; Grosskortenhaus et al., 2006). These factors, which are likely determined by clonal lineage, control aspects of both morphological and functional (electrical) development. Studies on motoneuron specification, from flies to mammals, have shown that early developmental decisions, such as subclass identity, are dictated, at least in part, by a combinatorial code of LIM-HD transcription factors (TFs) (Thor and

\footnotetext{
Received Oct. 23, 2013; revised Nov. 25, 2013; accepted Dec. 10, 2013.

Author contributions: V.W., T.D.S., C.G., A.A.P., A.H.B., and R.A.B. designed research; V.W., T.D.S., and C.G. performed research; V.W., T.D.S., and C.G. analyzed data; V.W., T.D.S., C.G., A.A.P., A.H.B., and R.A.B. wrote the paper.

This work was supported by The Wellcome Trust (090798 to R.A.B.; 068055/092545 to A.H.B.) and a Herchel Smith Postdoctoral Research Fellowship to T.D.S., C.G. was supported by the Epilepsy Foundation of America. A.H.B. was supported by the Gurdon Institute from The Wellcome Trust (092096) and CRUK (C6946/A14492). This project benefited from the Manchester Fly Facility, established by the University of Manchester and The Wellcome Trust (087742). We thank members of the R.A.B. and A.A.P. groups for advice.

The authors declare no competing financial interests.

This article is freely available online through the J Neurosci Author Open Choice option.

Correspondence should be addressed to Dr. Richard A. Baines, Faculty of Life Sciences, University of Manchester,

0xford Road, Manchester M13 9PT, United Kingdom. E-mail: Richard.Baines@manchester.ac.uk.

DOI:10.1523/JNEUROSCI.4511-13.2014

Copyright $\odot 2014$ Wolfram et al.

This is an Open Access article distributed under the terms of the Creative Commons Attribution License (http://creativecommons.org/licenses/by/3.0), which permits unrestricted use, distribution and reproduction in any medium provided that the original work is properly attributed.
}

Thomas, 1997; Landgraf et al., 1999; Dasen et al., 2005; Landgraf and Thor, 2006; Dasen et al., 2008; De Marco Garcia and Jessell, 2008). However, whether early neuron-type specific ion channel gene expression is similarly influenced through combinatorial activity of these same TFs remains to be demonstrated.

Embryonic Drosophila motoneurons express a stereotypic mix of identified TFs, which are evolutionary conserved with mammals (Thor and Thomas, 1997; Thaler et al., 1999; MoranRivard et al., 2001; Esmaeili et al., 2002; Thaler et al., 2002). For example, the RP subgroup of motoneurons (RPs 1, 3-5), which innervate ventral and lateral muscles, express the TFs Isl (also known as Tail-up), Lim3, and Hb9 (also known as Extra-extra). Motoneurons (e.g., aCC) that project dorsally express Eve (Thor and Thomas, 1997; Landgraf et al., 1999; Landgraf and Thor, 2006). The presence or absence of individual TFs, particularly Isl and Eve, is a known determinant for both axonal projection, neurotransmitter phenotype, and neuron type-specific expression of ion channels (Thor and Thomas, 1997; Landgraf et al., 1999; Pym et al., 2006; Wolfram et al., 2012).

Our previous studies used DNA adenine methyltransferase identification (DamID) (van Steensel and Henikoff, 2000) to identify ion channel genes, in particular slowpoke (slo) and Sh, as targets of Eve and Islet, respectively (Pym et al., 2006; Wolfram et al., 2012). Here we now report the complete identified DamIDderived binding sites for $\mathrm{Hb} 9$ and $\mathrm{Lim} 3$, together with a reassessment of DamID data previously obtained for Eve and Isl, using Flybase release 5.47. Our analysis identifies ion channel genes as 
targets of all four TFs, and shows that some ion channel genes (e.g., Sh) are bound by multiple TFs (in this instance, Isl and Lim3). We further show that the combined action of Isl and Lim3, in regulating Sh expression, is additive. As such, these findings provide first direct experimental evidence to support combinatorial regulation of a specific ion channel gene.

\section{Materials and Methods}

Fly stocks. Flies were maintained under standard conditions. For larval collections, flies were allowed to lay eggs onto grape juice agar plates. GAL4 $^{24 \mathrm{~B}}$ (homozygous viable on the second chromosome) was used to express isl ( $2 \times$ UAS-isl, third chromosome) or Lim3 (1× UAS-Lim3, second chromosome) in body wall muscle (both kindly supplied by Dr. Stefan Thor). Coexpression was achieved using a genetic cross containing both transgenes ( $2 \times$ UAS-isl and $1 \times$ UAS-Lim3). Embryos of either sex were kept at $18^{\circ} \mathrm{C}$ to avoid embryonic lethality, which occurs with expression of either transgene in muscle at $25^{\circ} \mathrm{C}$.

DamID analysis. The construction of DamID constructs and transgenic Drosophila lines has been previously described (Pym et al., 2006; Wolfram et al., 2012). Briefly, the full-length TF-coding sequences were PCR-amplified from an embryonic cDNA library and cloned into pUASTattB-NDam. Preparation of Dam-methylated DNA from stage 17 embryos was performed as previously described (Pym et al., 2006) and gene-targets identified (Wolfram et al., 2012) using Flybase release 5.47 and a stringent false discovery rate (FDR) of $0.1 \%$.

Electrophysiology. Hatched larvae (1-4 h old) were dissected and the CNS removed (Wolfram et al., 2012). Muscles were treated with $1 \mathrm{mg} / \mathrm{ml}$ collagenase (Sigma) for 0.5 to $1 \mathrm{~min}$ before whole-cell patch recording. Larvae were visualized using a water-immersion lens (total magnification, $600 \times$ ) combined with DIC optics (BX51W1 microscope; Olympus Optical). Recordings were made from muscle 6 in segments A3-4 using a Multiclamp 700B amplifier controlled by pClamp 10.2 (Molecular Devices). Recordings were sampled at $20 \mathrm{kHz}$ and filtered at $2 \mathrm{kHz}$. The voltage protocol used a maintained holding potential of $-60 \mathrm{mV}$ and a $-90 \mathrm{mV}$ prepulse for $200 \mathrm{~ms}$ before a $50 \mathrm{~ms}$ step to $40 \mathrm{mV}$. Leak currents were subtracted online $(\mathrm{P} / 4)$. Recordings were done in at least 4 animals, and at least 8 muscles were recorded from in total for each manipulation. Cell capacitance was determined by integrating the area under the capacity transients evoked by stepping from -60 to $-90 \mathrm{mV}$ (checked before and after recordings). External saline (Stewart et al., 1994) consisted of (in $\mathrm{mM}$ ) as follows: $70 \mathrm{NaCl}, 5 \mathrm{KCl}, 0.1 \mathrm{CaCl}_{2}, 20 \mathrm{MgCl}_{2} \cdot 6 \mathrm{H}_{2} \mathrm{O}, 10$ $\mathrm{NaHCO}_{3}, 5$ HEPES, 115 sucrose, 5 trehalose, $\mathrm{pH}$ 7.2. The calcium concentration was kept low to prevent activation of $\mathrm{Ca}^{2+}$-dependent $\mathrm{K}^{+}$ currents. Internal patch solution consisted of (in mM) as follows: 140 $\mathrm{K}^{+}$gluconate, $2 \mathrm{MgCl}_{2} \cdot 6 \mathrm{H}_{2} \mathrm{O}, 2 \mathrm{EGTA}, 5 \mathrm{KCl}$, and $20 \mathrm{HEPES}, \mathrm{pH} 7.4$.

Under conditions of low external $\mathrm{Ca}^{2+}$, recorded traces contained two types of $\mathrm{K}^{+}$conductances: Kfast (Kf) inactivating type (carried by Sh) and a Kslow (Ks) noninactivating type. These can be separated based on holding potential: $\mathrm{Kf}$ is inactivated by sustained depolarization (Wu and Haugland, 1985). We find, however, that inactivation is often incomplete resulting in variability of separation. Thus, we adopted a computational approach. To determine magnitude of Kf, we fitted data to standard Hodgkin-Huxley ion channel models of the form: $I=\bar{g} m^{4} h(V-E)$. We first fitted the kinetic parameters of both $\mathrm{Kf}$ and Ks simultaneously. The reversal potential was found as $E=-67$ $\mathrm{mV}$. Channel activation $(m)$ and inactivation $(h)$ gates were calculated with $d m / d t=\left(m_{\infty}-m\right) / \tau_{m}$. The steady state for activation was defined as $m_{\infty}=1 /\left(1+\exp \left(\left(V-V_{1 / 2}\right) / k\right)\right)$, and we found $\mathrm{Kf}$ to have $V_{1 / 2}=$ $-25.1 \mathrm{mV}$ and $k=-12.0 \mathrm{mV}$, and $\mathrm{Ks}$ to have $V_{1 / 2}=5.4 \mathrm{mV}$ and $k=-24.7 \mathrm{mV}$. The time constant was defined by $\tau_{m}=a+b /$ $(1+\exp ((V+c) / d))$, and $(a, b, c, d)$ was found for $\mathrm{Kf}$ as $(3.15,104.0$, $66.2,25.6)$ and for $\mathrm{Ks}$ as $(2.7,1.4,-78.0,0.13)$. For inactivation of $\mathrm{Kf}$, we found $V_{1 / 2}=-60 \mathrm{mV}$ and $k=6 \mathrm{mV}$, and $(1.53,7.62,27.63,26.12)$ for the time constant. Once this fit was achieved, it was used as a template. To measure change in magnitude of $\mathrm{Kf}$, we allowed only the parameters of maximal conductance, $\bar{g}$, for each channel and time constant offset, $a$, for each gate, to vary. We used a nonlinear least-squares fitter (lsqcurvefit function) in MATLAB (MathWorks) that uses the large-scale trust- region reflective Newton method. The 95\% confidence intervals of individual fits were observed and bad fits rejected. Once parameters for $\mathrm{Kf}$ were fitted for a given experiment, we calculated a "peak conductance" in $\mathrm{nS}$ by calculating the value of $g=\bar{g} m^{4} h$ at time of the expected peak, $t_{\text {pcak }}=\tau_{m} \log \left(\frac{\tau_{m}+p \tau_{h}}{\tau_{m}}\right)$, where $p=4$ is the power of the activation gate, $m$.

$q R T-P C R$. Muscle tissue was collected from newly hatched larvae. After RNA extraction (QIAGEN RNaesy Micro kit), cDNA was synthesized using the Fermentas Reverse Aid H minus First strand cDNA synthesis kit. RNA concentration was matched for control and experimental samples before cDNA synthesis. qRT-PCR was performed on a Roche LightCycler480 II (Roche) in dual-color mode using the LightCycler TaqMan Master reaction mix (Roche; 04535286001). The thermal profile used was $10 \mathrm{~min}$ at $95^{\circ} \mathrm{C}$ followed by 45 cycles of $10 \mathrm{~s}$ at $95^{\circ} \mathrm{C}$, followed by $20 \mathrm{~s}$ at $60^{\circ} \mathrm{C}$, and finally $10 \mathrm{~s}$ at $72^{\circ} \mathrm{C}$. Results were analyzed by the $\Delta / \Delta \mathrm{C}_{t}$ method and are expressed as fold difference relative to control. $C_{t}$ values used were the means of duplicates. TaqMan primers and probes (forward and reverse primers in $5^{\prime}$ to $3^{\prime}$ orientation) were as follows: rp49 primers CCAGTCGGATCGATCGATATGCTA and ACGTTGTGCACCAGGAA and probe GATGCCCAACATCGGTTACGG conjugated with Cy5; Sh primers TAGGTGATCAAGCAATTAATAAATTCAG and TAACAAA TACACTAATTATGGCTACAACT and probe AGACCATTACCGGA TAATGAGAAACAGAG conjugated with FAM. Levels of expressed transcription factor in muscle were also monitored by TaqMan qPCR.

Statistics. Statistical significance was calculated using a one-way ANOVA with Tukey's post hoc test using confidence intervals of $p \leq 0.05$ and $p \leq 0.01$. All quantitative data shown are mean \pm SEM.

Accession codes. The DamID-chip data have been deposited under NCBI GEO accession GSE53446.

\section{Results}

\section{Target genes include both ion channel and morphology- associated genes}

The LIM-HD transcription factors Isl and Eve control both axon guidance and ion-channel expression in developing neurons (Thor and Thomas, 1997; Landgraf et al., 1999; Pym et al., 2006; Wolfram et al., 2012). Together with other motoneuronexpressed TFs, notably Lim3 and Hb9, these TFs have been postulated to act combinatorially to set both structural and functional properties of embryonic neurons (Landgraf and Thor, 2006; Wolfram and Baines, 2013). However, to date, the gene targets of these TFs remain largely unknown and combinatorial activity remains to be definitively shown. We used DamID to describe binding sites for each of these TFs in Drosophila. Using an FDR of $\leq 0.1 \%$, we identify 2670 genes (exhibiting one or more peaks of binding within $5 \mathrm{~kb}$ of the transcriptional unit) as targets of Isl; 4105 genes for Lim3, 1771 genes for $\mathrm{Hb} 9$, and 1039 genes for Eve. Notably, Islet, Lim3, and Hb9 bind a comparatively larger number of gene targets than does Eve. Analysis of targets indicates that these three TFs share a large number of common putative targets. In contrast, overlap with targets of Eve is relatively much smaller. This is predictable and validates our analysis because it reflects the observed overlap in neuron expression of these transcription factors. Lim3, Isl, and Hb9 are found colocalized in many motoneurons, whereas Eve is expressed in relatively few (Landgraf and Thor, 2006).

Consistent with the possibility of combinatorial regulation, many of target genes are bound by more than one TF (Fig. 1; Table 1). Gene ontology analysis reveals that targets include ion channels and also genes associated with both morphology (axonal and dendritic) and synapse formation (Table 1). This latter subset includes beat-Ic, Dscam, fra, Fas2, robo, and Sema1 a, which have been studied in some detail (Baines et al., 2002; Corty et al., 2009; Mauss et al., 2009; Timofeev et al., 2012). One gene in 


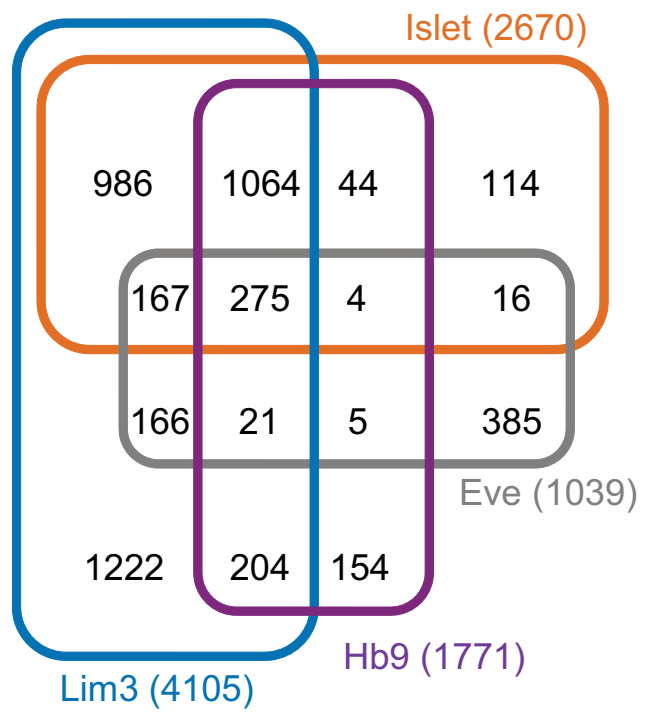

Figure 1. Overlap of putative gene targets of $|\mathrm{s}| \mathrm{L}, \mathrm{Lim} 3, \mathrm{Hb}$, and Eve determined by DamID. A four-way Venn diagram showing numbers of gene targets identified for each TF and overlap.

particular, beat- $I c$, has been shown to be downstream of the LIM-HD combinatorial code: regulation in this instance dictating motoneuron synaptic connectivity (Certel and Thor, 2004).

Of the ion channel gene targets identified, there is considerable evidence to show that the voltage-gated $\mathrm{K}^{+}$channel genes, Sh, Shal, Shab, the $\mathrm{Ca}^{2+}$-dependent $\mathrm{K}^{+}$channel gene slo, and the $\mathrm{Ca}^{2+}$-channel gene $\mathrm{Ca}-\alpha 1 \mathrm{D}$ are expressed in motoneurons (Byerly and Leung, 1988; Leung and Byerly, 1991; Martínez-Padrón and Ferrús, 1997; Baines and Bate, 1998; Engel and Wu, 1998; Worrell and Levine, 2008). Synaptic excitation of motoneurons is also cholinergic (Baines et al., 1999); and in this regard, it is significant that our analysis identifies 5 nicotinic receptorsubunits (of a total of 10) (Sattelle et al., 2002). These genes are $n A c R \alpha-30 D, n A c R \alpha-7 E, n A c R \alpha-34 E, n A c R \alpha-96 A a$, and $n A c R \beta-$ 96A. We have previously validated three of the identified ion channel genes, Sh and slo/nAcR $\alpha-96 A \alpha$, as targets of Isl and Eve, respectively (Pym et al., 2006; Wolfram et al., 2012). It should be noted, however, that slo is now only identified (using stricter reassessment criteria) when we relax the FDR to $\leq 0.5 \%$, indicative that our current target list (derived from an FDR of $\leq 0.1 \%$ ) is restricted.

\section{Combinatorial transcription factors share the same targets}

Our DamID shows that some genes are potentially bound by more than one TF. For example, $S h$ is a validated target of Isl (Wolfram et al., 2012) but also a putative target of Lim3 (Fig. 2; Table 1). Significantly, a mammalian Isl1:LhX3 (Isl/Lim3 homologs) ATTAGTTAATT "dimer" motif (Lee et al., 2008) underlies both Isl and Lim3 binding sites at this locus (Fig. 2). This overlap is consistent with the hypothesis of combinatorial regulation. We tested for this experimentally.

To determine how Lim3 influences expression of $S h$ and whether its effect is additive to that of Isl, we used body wall muscle in which $\mathrm{Kf}$ is carried entirely by Sh channels (in low external $\mathrm{Ca}^{2+}$ ) (Singh and $\mathrm{Wu}, 1990$ ). Such analysis would be complicated in neurons because of the expression of an additional Kf encoded by Shal (Tsunoda and Salkoff, 1995) and homeostatic mechanisms (Baines et al., 2001), which maintain consistency in action potential firing through adjustment of ionic
Table 1. Selected genes identified by DamID as putative targets of Islet, Lim3, Hb9, and Eve

\begin{tabular}{|c|c|c|c|c|}
\hline Gene & Islet & $\operatorname{Lim} 3$ & $\mathrm{Hb} 9$ & Eve \\
\hline Sh & $\checkmark$ & $\checkmark$ & & \\
\hline Shab & $\sqrt{ }$ & $\sqrt{ }$ & & $\sqrt{ }$ \\
\hline Shawl & & & & $\sqrt{ }$ \\
\hline Shal & $\checkmark$ & $\checkmark$ & $\checkmark$ & \\
\hline slo & & $\sqrt{ }$ & & $\sqrt{ }$ \\
\hline SK & $\sqrt{ }$ & $\checkmark$ & & $\sqrt{ }$ \\
\hline KCNQ & $\checkmark$ & $\checkmark$ & & \\
\hline Ih & $\sqrt{ }$ & $\sqrt{ }$ & & \\
\hline Ca-alpha1T & $\sqrt{ }$ & $\sqrt{ }$ & $\checkmark$ & \\
\hline Ca-alpha1D & $\sqrt{ }$ & $\sqrt{ }$ & & \\
\hline Ca-beta & J & $\checkmark$ & & \\
\hline $\mathrm{nAcR} \alpha-7 \mathrm{E}$ & $\sqrt{ }$ & $\checkmark$ & $\sqrt{ }$ & $\sqrt{ }$ \\
\hline $\mathrm{nAcR} \alpha-30 \mathrm{D}$ & $\sqrt{ }$ & $\checkmark$ & & \\
\hline $\mathrm{nAcR} \alpha-34 \mathrm{E}$ & $\sqrt{ }$ & $\sqrt{ }$ & $\checkmark$ & $\sqrt{ }$ \\
\hline $\mathrm{nAcR} \alpha-96 \mathrm{Aa}$ & & $\sqrt{ }$ & & $\sqrt{ }$ \\
\hline $\mathrm{nAcR} \beta-96 \mathrm{~A}$ & & $\sqrt{ }$ & & \\
\hline beat-la & $\checkmark$ & $\checkmark$ & & \\
\hline beat-lb & $\sqrt{ }$ & $\checkmark$ & & $\sqrt{ }$ \\
\hline beat-Ic & & $\checkmark$ & & \\
\hline beat-Ila & $\sqrt{ }$ & $\checkmark$ & & \\
\hline beat-Ilb & & $\sqrt{ }$ & & $\sqrt{ }$ \\
\hline beat-IIla & & $\sqrt{ }$ & & \\
\hline beat-IIlc & $\checkmark$ & $\sqrt{ }$ & $\sqrt{ }$ & \\
\hline beat-Vb & & $\sqrt{ }$ & & \\
\hline beat-Vc & & $\sqrt{ }$ & & $\sqrt{ }$ \\
\hline beat-VI & & $\sqrt{ }$ & & $\sqrt{ }$ \\
\hline beat-VII & & $\sqrt{ }$ & & \\
\hline Sema-1a & $\checkmark$ & $\sqrt{ }$ & $\checkmark$ & $\sqrt{ }$ \\
\hline Sema-1b & $\sqrt{ }$ & $\sqrt{ }$ & $\sqrt{ }$ & \\
\hline Sema-2a & $\sqrt{ }$ & $\checkmark$ & & $\checkmark$ \\
\hline Sema-2b & $\sqrt{ }$ & $\checkmark$ & & $\sqrt{ }$ \\
\hline Sema-5c & $\checkmark$ & $\sqrt{ }$ & $\checkmark$ & $\sqrt{ }$ \\
\hline NetA & $\sqrt{ }$ & $\sqrt{ }$ & $\checkmark$ & \\
\hline NetB & $\sqrt{ }$ & $\sqrt{ }$ & & $\checkmark$ \\
\hline fra & $\sqrt{ }$ & $\checkmark$ & $\checkmark$ & \\
\hline unc -5 & $\sqrt{ }$ & $\checkmark$ & $\checkmark$ & \\
\hline robo & $\sqrt{ }$ & $\checkmark$ & $\sqrt{ }$ & \\
\hline robo3 & & $\sqrt{ }$ & & \\
\hline Dscam & $\checkmark$ & $\checkmark$ & $\checkmark$ & \\
\hline Fas1 & $\sqrt{ }$ & $\sqrt{ }$ & $\sqrt{ }$ & \\
\hline Fas2 & $\sqrt{ }$ & $\sqrt{ }$ & $\checkmark$ & \\
\hline Fas3 & $\checkmark$ & $\checkmark$ & $\checkmark$ & $\checkmark$ \\
\hline comm & & $\checkmark$ & $\sqrt{ }$ & \\
\hline Lar & & $\checkmark$ & $\sqrt{ }$ & $\sqrt{ }$ \\
\hline shot & $\sqrt{ }$ & $\sqrt{ }$ & $\checkmark$ & $\checkmark$ \\
\hline
\end{tabular}

conductances. By contrast, muscle does not exhibit this type of homeostasis. To determine the amplitude of Kf in muscle wholecell recordings, we modeled $\mathrm{Kf}$ and $\mathrm{Ks}$, which allowed us to computationally determine peak conductances for both (see Materials and Methods). As previously shown, expression of isl in muscle is sufficient to reduce both the magnitude of $\mathrm{Kf}$ (Shdependent) (Fig. $3 A-C$ ) and the abundance of Sh transcript (Fig. $3 D$ ) consistent with transcriptional regulation (Wolfram et al., 2012). Expression of $i s l$ led to a significant reduction of Kf $(0.17 \pm$ 0.02 vs $0.11 \pm 0.01 \mathrm{nS}, p=0.01, n \geq 8$, mean $\pm \mathrm{SE}$ ) and transcript $(0.91 \pm 0.03$-fold difference, $p=0.02, n=6)$. By contrast, expression of $\operatorname{Lim} 3$ did not statistically affect either $\operatorname{Kf}(0.13 \pm 0.01$ nS, $p=0.08, n=10)$ or Sh transcript level $(0.94 \pm 0.03$-fold reduction, $p=0.1$; Fig. 2 ), even though the Lim3 transgene was expressed at increased levels relative to isl $(\sim 30$-fold compared with an $\sim 15$-fold increase relative to control, no transgenic expression). Coexpression of both isl and Lim3 was, however, suf- 


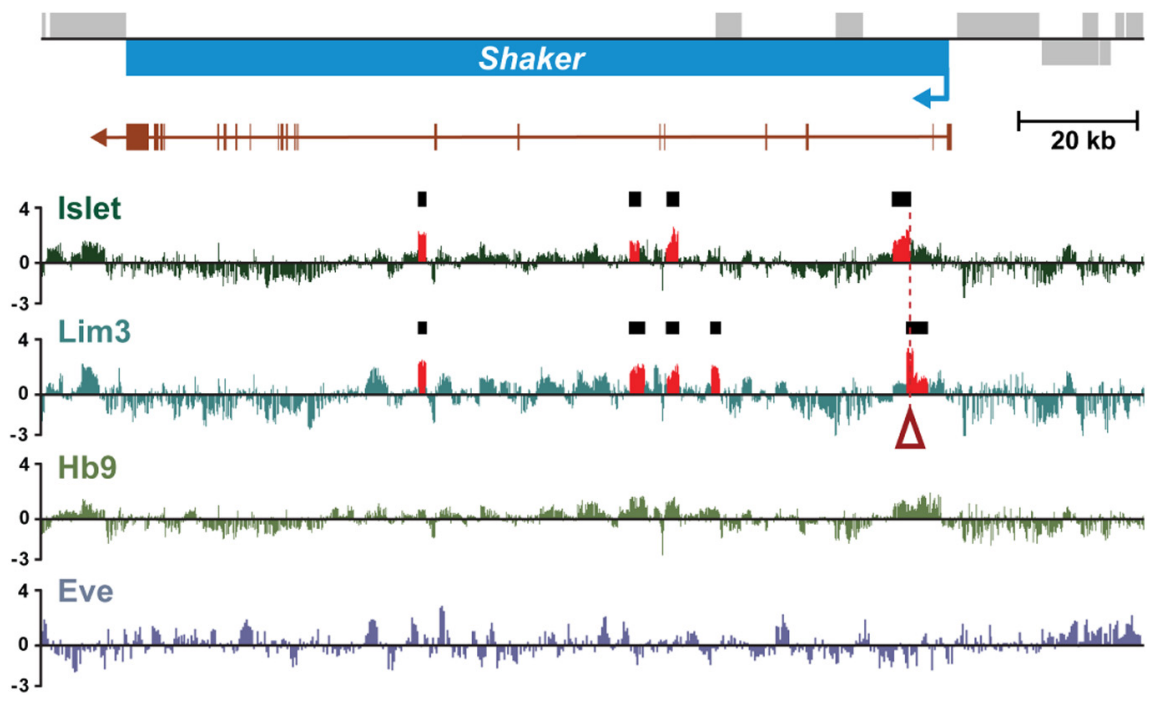

Figure 2. DamID demonstrates direct binding of Isl and Lim3 to the Sh locus. The transcription unit of $S h$ is shown in blue; arrow indicates direction of transcription. Sh exons are shown immediately below in brown. Putative binding of each TF to this locus is indicted by the average of normalized log2-transformed ratios from multiple independent DamID experiments. Areas in red (and marked by the black boxes) represent a significant binding peak within the dataset (FDR $<0.1 \%$ ) for both Is and Lim3. No binding peaks were detected for $\mathrm{Hb} 9$ and Eve. Open red arrow indicates the location of a mammalian Is|1:LhX3 (IsI/Lim3 homologs) ATTAGTTAATT "dimer" motif (Lee et al., 2008).
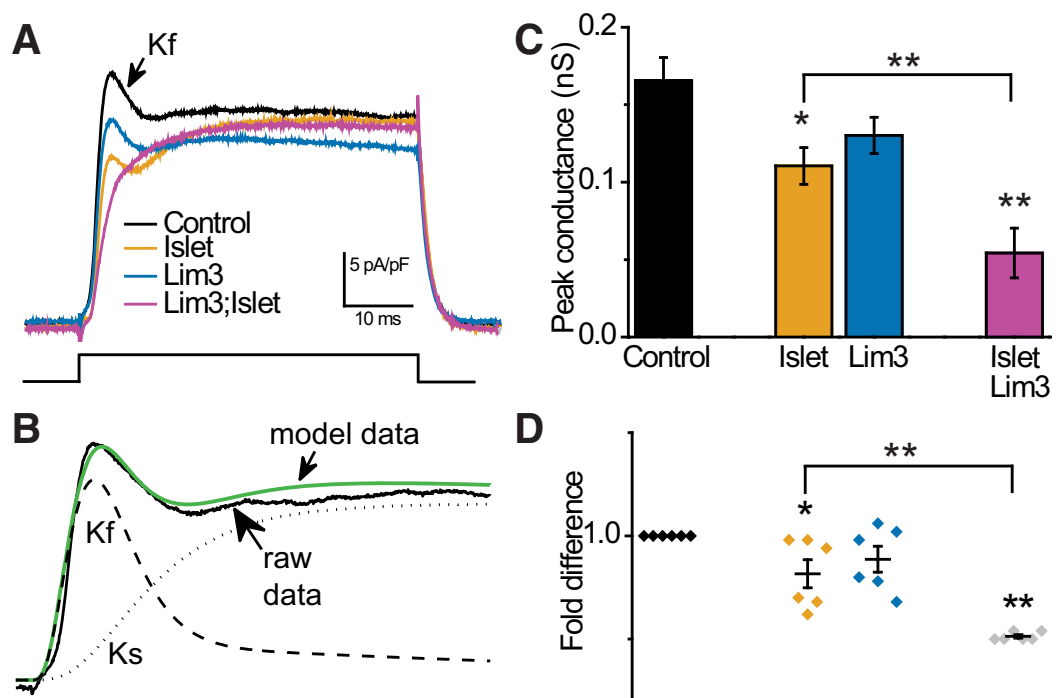

D

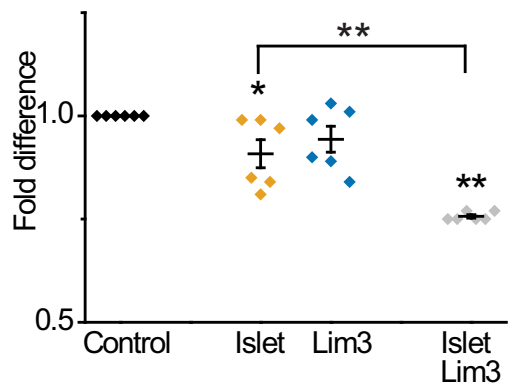

Figure 3. Islet and Lim 3 act combinatorially to regulate Sh expression. $A$, The fast $\mathrm{K}^{+}$current $(\mathrm{Kf})$ in body wall muscle is carried entirely by the $\mathrm{Sh}$ channel (in conditions of low $\mathrm{Ca}^{2+}$ ). Traces represent membrane current produced under voltage clamp for a step from -90 to $40 \mathrm{mV}$ for $50 \mathrm{~ms}$ in control muscle and when Isl, Lim3, or both are expressed. Recordings are normalized to cell capacitance. $\boldsymbol{B}$, Modeling of the outward $\mathrm{K}^{+}$conductance allows Kf (carried by Sh) and Kslow (Ks) to be differentiated. Green line indicates model fit to capacitance-adjusted data (control muscle); model-derived Kf and Ks are shown. C, Model-derived peak conductances for Kf show that expression of Is I is sufficient to suppress the Sh-dependent Kf current, whereas Lim3 expression has no statistically significant effect. Coexpression of both IsI and Lim3 further reduces $\mathrm{Kf}$ to a level that is significantly different from Isl. D, qPCR shows that coexpression of Isl and Lim 3 reduces $S h$ transcript to a level significantly different from Isl expression alone. In isolation, only Isl expression significantly reduces Sh transcript levels, mirroring the effect on Sh current. Values are mean \pm SEM. ${ }^{*} p \leq 0.05 .{ }^{* *} p \leq 0.01$.

ficient to reduce both $\mathrm{Kf}(0.05 \pm 0.02 \mathrm{nS}, p=0.001, n=9)$ and $S h$ transcript $\left(0.76 \pm 0.004\right.$-fold reduction, $\left.p=6 \times 10^{-14}, n=6\right)$ by an amount significantly greater than observed with isl alone $(p=$ 0.015 for $\mathrm{Kf}$ and $p=0.001$ for transcript; Fig. 3). In these coexpression experiments, qRT-PCR shows that both $\operatorname{Lim} 3$ and isl are up-regulated by $\sim 8$ - and $\sim 12$-fold, relative to control. It should be noted that DamID shows that $\operatorname{Lim} 3$ is bound by Islet, which likely explains the significantly lower expression level compared with when $\operatorname{Lim} 3$ was overexpressed alone.

Together, our results are consistent with the previous demonstration of a direct gene-dosage relationship between $S h$ transcript and Sh-dependent Kf expressed in body wall muscle (Haugland and $\mathrm{Wu}$, 1990). Attempts to verify this through higher TF transgene expression, often achieved by raising the temperature to $25^{\circ} \mathrm{C}$, was not possible in our experiments because of lethality at this temperature. Thus, we conclude that repression of $S h$ expression by coexpressing both isl and Lim3 is additive, which is both predictive and supportive of combinatorial regulation.

\section{Discussion}

In contrast to specification of neuron identity, little is known concerning how embryonic neurons regulate ion channel gene expression before formation of neural networks. Recent studies, in a range of animals, suggest that members of a defined set of LIM-HD TFs regulate this early phase of expression. Collectively, these studies have led to the proposition that early neuron-type specific properties, including axonal and dendritic morphology, choice of synaptic target and expression of ion channels, are set by a combinatorial activity of TFs (Landgraf and Thor, 2006; Pym et al., 2006; Wolfram et al., 2012). For example, the presence of Lim3 is seemingly sufficient to subdivide Drosophila Isl-positive motoneurons into the ISNb and ISNd classes (Thor et al., 1999). Although there is evidence to show that ion channels are also regulated by LIM-HD TFs (Wolfram and Baines, 2013), definitive evidence to show combinatorial regulation is lacking. In this study, we show that the activity of two early expressed combinatorial TFs, Isl and Lim3, is additive such that their combined effect to suppress expression of the $\mathrm{Sh} \mathrm{K}^{+}$ channel is significantly greater than either alone.

To show that $S h$ expression is regulated by both Isl and Lim3, we exploited muscle as a model tissue. There are several advantages of using muscle over neurons. First, $\mathrm{Kf}$ in muscle (in conditions of low external $\mathrm{Ca}^{2+}$ ) is carried solely by Sh channels (Singh and Wu, 1990). Second, muscle is isopotential (Jan and Jan, 1976), which significantly minimizes the impact of space clamp problems, which, in neurons, can be particularly problematic for fine-scale analysis of ionic currents. Third, studies in neurons can be complicated by 
homeostatic mechanisms, which maintain consistency in action potential firing. These mechanisms, not present in muscle, can modify expression of other channels to compensate for any enforced perturbation to membrane excitability that would be caused, in this instance, by manipulation of Sh expression (Baines et al., 2001; Wolfram et al., 2012). Validation of the effects we report here in muscle will, of course, require analysis of the effect of TF expression in central neurons. An attractive possibility, if endogenous levels of individual TFs can be accurately determined, is to use our understanding of Isl and Lim 3 to predict levels of Shdependent $\mathrm{K}^{+}$current in individual motoneurons, which can be subsequently confirmed by electrophysiology.

An important question to be addressed is how coexpression of Isl and Lim3 differs from expression of Isl alone in being able to repress Sh expression. The mammalian homologs, Isl1 and LhX3, have been shown to form a hexameric complex, together with the self-dimerizing cofactor NL1, to promote motoneuron fate (Lee et al., 2012). Although the LhX3/Isl1 complex and Isl1 or LhX3 response elements share $\mathrm{A} / \mathrm{T}$-rich sequences, each site is unique (Lee et al., 2008). Isl1 binds a DNA motif containing a core TAAT sequence (Yaden et al., 2005; Lee et al., 2008; Mazzoni et al., 2013). TAAT motif sites occur at a very high frequency in the genome; therefore, examining this site alone is not particularly informative. The first report to describe an Isll binding site (Boam and Docherty, 1989) identified a CTAATG, which is present at one of the sites of Isl binding at the Sh locus. Lee et al. (2008) reported a predicted site for LhX3 binding (AATTAATTA) and a hybrid motif (ATTAGCNTAATT), which is bound by Isl1:LhX3 dimers. We do not observe the Lhx3 (i.e., Lim3) motif but do find a highly similar ATTAGTTAATT "dimer" motif at a site where both Isl and Lim3 bind the Sh locus (coordinates 1795073517950745; Fig. 2). Our identification of multiple genes for Isl and Lim3 in Drosophila affords significant opportunities to refine the identification of response elements in this model genome. This may allow identification of not only additional gene targets but will also have significant comparative value for identification of mammalian response elements.

In conclusion, sufficient studies have been reported to show that the TFs required for specification of neuron identity, such as Isl, Lim3, Hb9, and Eve, are present in all nervous systems and, moreover, that the developmental mechanisms they regulate are conserved. Our present DamID results, together with previous studies (Pym et al., 2006; Wolfram et al., 2012), provide experimental evidence that these regulatory factors orchestrate significant aspects of both the morphological and electrical development of embryonic neurons. For at least one gene, but likely more, this regulation is likely combinatorial. The use of Drosophila to describe the gene targets and underlying mechanisms through which these TFs operate will make a significant advance to understanding of neural circuit development.

\section{References}

Baines RA, Bate M (1998) Electrophysiological development of central neurons in the Drosophila embryo. J Neurosci 18:4673-4683. Medline

Baines RA, Robinson SG, Fujioka M, Jaynes JB, Bate M (1999) Postsynaptic expression of tetanus toxin light chain blocks synaptogenesis in Drosophila. Curr Biol 9:1267-1270. CrossRef Medline

Baines RA, Uhler JP, Thompson A, Sweeney ST, Bate M (2001) Altered electrical properties in Drosophila neurons developing without synaptic transmission. J Neurosci 21:1523-1531. Medline

Baines RA, Seugnet L, Thompson A, Salvaterra PM, Bate M (2002) Regulation of synaptic connectivity: levels of Fasciclin II influence synaptic growth in the Drosophila CNS. J Neurosci 22:6587-6595. Medline

Boam DS, Docherty K (1989) A tissue-specific nuclear factor binds to mul- tiple sites in the human insulin-gene enhancer. Biochem J 264:233-239. Medline

Byerly L, Leung HT (1988) Ionic currents of Drosophila neurons in embryonic cultures. J Neurosci 8:4379-4393. Medline

Certel SJ, Thor S (2004) Specification of Drosophila motoneuron identity by the combinatorial action of POU and LIM-HD factors. Development 131:5429-5439. CrossRef Medline

Corty MM, Matthews BJ, Grueber WB (2009) Molecules and mechanisms of dendrite development in Drosophila. Development 136:1049-1061. CrossRef Medline

Dasen JS, Tice BC, Brenner-Morton S, Jessell TM (2005) A Hox regulatory network establishes motor neuron pool identity and target-muscle connectivity. Cell 123:477-491. CrossRef Medline

Dasen JS, De Camilli A, Wang B, Tucker PW, Jessell TM (2008) Hox repertoires for motor neuron diversity and connectivity gated by a single accessory factor, FoxP1. Cell 134:304-316. CrossRef Medline

De Marco Garcia NV, Jessell TM (2008) Early motor neuron pool identity and muscle nerve trajectory defined by postmitotic restrictions in Nkx6.1 activity. Neuron 57:217-231. CrossRef Medline

Engel JE, Wu CF (1998) Genetic dissection of functional contributions of specific potassium channel subunits in habituation of an escape circuit in Drosophila. J Neurosci 18:2254-2267. Medline

Esmaeili B, Ross JM, Neades C, Miller DM 3rd, Ahringer J (2002) The C. elegans even-skipped homologue, vab-7, specifies DB motoneurone identity and axon trajectory. Development 129:853-862. Medline

Grosskortenhaus R, Pearson BJ, Marusich A, Doe CQ (2005) Regulation of temporal identity transitions in Drosophila neuroblasts. Dev Cell 8:193202. CrossRef Medline

Grosskortenhaus R, Robinson KJ, Doe CQ (2006) Pdm and Castor specify late-born motor neuron identity in the NB7-1 lineage. Genes Dev 20: 2618-2627. CrossRef Medline

Haugland FN, Wu CF (1990) A voltage-clamp analysis of gene-dosage effects of the Shaker locus on larval muscle potassium currents in Drosophila. J Neurosci 10:1357-1371. Medline

Jan LY, Jan YN (1976) Properties of the larval neuromuscular junction in Drosophila melanogaster. J Physiol 262:189-214. Medline

Landgraf M, Thor S (2006) Development of Drosophila motoneurons: specification and morphology. Semin Cell Dev Biol 17:3-11. CrossRef Medline

Landgraf M, Roy S, Prokop A, VijayRaghavan K, Bate M (1999) Evenskipped determines the dorsal growth of motor axons in Drosophila. Neuron 22:43-52. CrossRef Medline

Lee S, Lee B, Joshi K, Pfaff SL, Lee JW, Lee SK (2008) A regulatory network to segregate the identity of neuronal subtypes. Dev Cell 14:877-889. CrossRef Medline

Lee S, Cuvillier JM, Lee B, Shen R, Lee JW, Lee SK (2012) Fusion protein Isl1-Lhx3 specifies motor neuron fate by inducing motor neuron genes and concomitantly suppressing the interneuron programs. Proc Natl Acad Sci U S A 109:3383-3388. CrossRef Medline

Leung HT, Byerly L (1991) Characterization of single calcium channels in Drosophila embryonic nerve and muscle cells. J Neurosci 11:3047-3059. Medline

Martínez-Padrón M, Ferrús A (1997) Presynaptic recordings from Drosophila: correlation of macroscopic and single-channel $\mathrm{K}^{+}$currents. J Neurosci 17:3412-3424. Medline

Mauss A, Tripodi M, Evers JF, Landgraf M (2009) Midline signalling systems direct the formation of a neural map by dendritic targeting in the Drosophila motor system. PLoS Biol 7:e1000200. CrossRef Medline

Mazzoni EO, Mahony S, Closser M, Morrison CA, Nedelec S, Williams DJ, An D, Gifford DK, Wichterle H (2013) Synergistic binding of transcription factors to cell-specific enhancers programs motor neuron identity. Nat Neurosci 16:1219-1227. CrossRef Medline

Moran-Rivard L, Kagawa T, Saueressig H, Gross MK, Burrill J, Goulding M (2001) Evxl is a postmitotic determinant of v0 interneuron identity in the spinal cord. Neuron 29:385-399. CrossRef Medline

Pym EC, Southall TD, Mee CJ, Brand AH, Baines RA (2006) The homeobox transcription factor Even-skipped regulates acquisition of electrical properties in Drosophila neurons. Neural Dev 1:3. CrossRef Medline

Sattelle DB, Culetto E, Grauso M, Raymond V, Franks CJ, Towers P (2002) Functional genomics of ionotropic acetylcholine receptors in Caenorhabditis elegans and Drosophila melanogaster. Novartis Found Symp 245: 240-257; discussion 257-260. 
Singh S, Wu CF (1990) Properties of potassium currents and their role in membrane excitability in Drosophila larval muscle fibers. J Exp Biol 152: 59-76. Medline

Spana EP, Kopczynski C, Goodman CS, Doe CQ (1995) Asymmetric localization of numb autonomously determines sibling neuron identity in the Drosophila CNS. Development 121:3489-3494. Medline

Stewart BA, Atwood HL, Renger JJ, Wang J, Wu CF (1994) Improved stability of Drosophila larval neuromuscular preparations in haemolymphlike physiological solutions. J Comp Physiol A Neuroethol Sens Neural Behav Physiol 175:179-191. CrossRef Medline

Thaler JP, Lee SK, Jurata LW, Gill GN, Pfaff SL (2002) LIM factor Lhx3 contributes to the specification of motor neuron and interneuron identity through cell-type-specific protein-protein interactions. Cell 110:237249. CrossRef Medline

Thaler J, Harrison K, Sharma K, Lettieri K, Kehrl J, Pfaff SL (1999) Active suppression of interneuron programs within developing motor neurons revealed by analysis of homeodomain factor HB9. Neuron 23:675-687. CrossRef Medline

Thor S, Thomas JB (1997) The Drosophila islet gene governs axon pathfinding and neurotransmitter identity. Neuron 18:397-409. CrossRef Medline

Thor S, Andersson SG, Tomlinson A, Thomas JB (1999) A LIM-homeodomain combinatorial code for motor-neuron pathway selection. Nature 397:76-80. CrossRef Medline

Timofeev K, Joly W, Hadjieconomou D, Salecker I (2012) Localized netrins act as positional cues to control layer-specific targeting of photoreceptor axons in Drosophila. Neuron 75:80-93. CrossRef Medline

Tsunoda S, Salkoff L (1995) Genetic analysis of Drosophila neurons: Shal, Shaw, and Shab encode most embryonic potassium currents. J Neurosci 15:1741-1754. Medline

van Steensel B, Henikoff S (2000) Identification of in vivo DNA targets of chromatin proteins using tethered dam methyltransferase. Nat Biotechnol 18:424-428. CrossRef Medline

Wolfram V, Baines RA (2013) Blurring the boundaries: developmental and activity-dependent determinants of neural circuits. Trends Neurosci 36: 610-619. CrossRef Medline

Wolfram V, Southall TD, Brand AH, Baines RA (2012) The LIM-homeodomain protein islet dictates motor neuron electrical properties by regulating $\mathrm{K}(+)$ channel expression. Neuron 75:663-674. CrossRef Medline

Worrell JW, Levine RB (2008) Characterization of voltage-dependent $\mathrm{Ca}^{2+}$ currents in identified Drosophila motoneurons in situ. J Neurophysiol 100:868-878. CrossRef Medline

Wu CF, Haugland FN (1985) Voltage-clamp analysis of membrane currents in larval muscle fibers of Drosophila: alteration of potassium currents in Shaker mutants. J Neurosci 5:2626-2640. Medline

Yaden BC, Savage JJ, Hunter CS, Rhodes SJ (2005) DNA recognition properties of the LHX3b LIM homeodomain transcription factor. Mol Biol Rep 32:1-6. CrossRef Medline 